61 レーザー誘起蛍光法による逆噴射ジェトの可視化実験

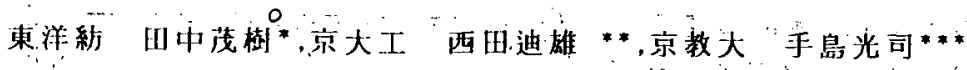

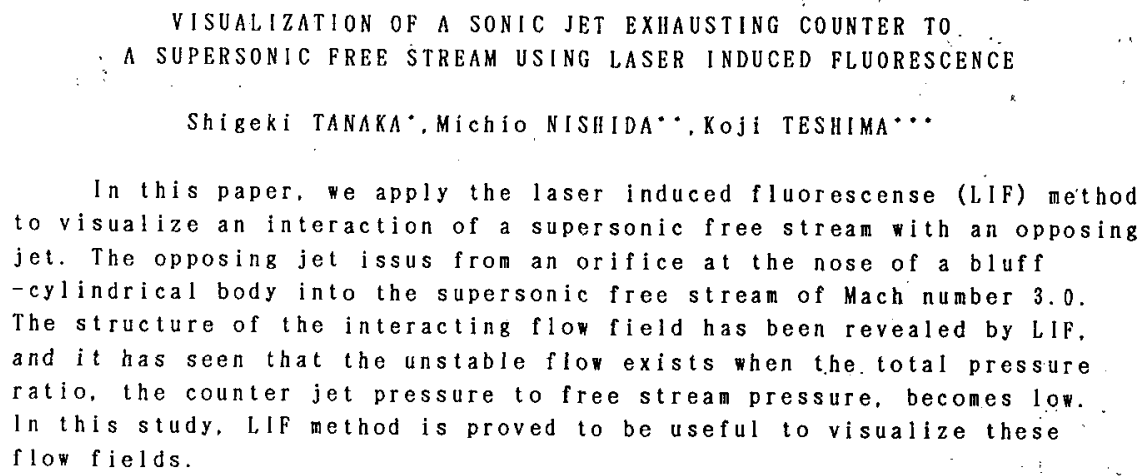

\title{
1.はじめに
}

逆謝ジェットの問題については1959年後期から1960年代初期にかけてその先駆的研究 がなされ、いー6)超音速一样流とジェットの干渉の流れ場の構造が解明された。その後も この問題に関して興味がもたれ、実缺と数值シミュレーションによりさらに詳細な研究が 行なわれてきた。ヤーい最近SCRAMJETやAOTVに関連して、再びこの問題の重要性茄認めら れるようになった。超音速流と逆噴射シェットとの干涉現象を把握するため従来、多ェう ーレン法が用いられてきたが、対象となる流れが軸対称であるので、結果は流れを横切っ て稹分した結果であった。

本報ではレーザー誘起蛍光法を用いて、超音速一样流中に設犆された平頍物体モデルか らの逆噴射シェットの二次元的な面での流扎の構造を把握しょうとした。

\section{2. 可視化実験}

レーザー誘起蛍光法 ${ }^{12)}$ はヨウ素I $\mathrm{I}_{2} に$ 波長514.5nm のアルコンイオンレーザーを照射す ると萤光を発することを利用するもので、試駼気体中に微量のI 2 を加えることにより流れ は何ら影墏を受けないで流れの可視化を行うことができる。 
レーザー誘起蛍光法の装 篔概要を図1に示す。ノス ル出口径6.78 $\mathrm{mm}$ の P L スルに上って超音速一㦈流

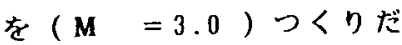
した。その流れの中に外径 $2.0 \mathrm{~mm}$,オリフィス径 $0.4 \mathrm{~mm}$ の网柱状の逆噴射ジェット ノズルをJPLノズルの下 流 $3 \mathrm{~mm}$ の位㦈に鵝えつけて 所定の压力で逆櫴射を行っ た。二つのノズルの配置を 四2に示す。作動気体はJ PLノズルおよび逆犆射ノ

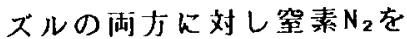
用い、眝気棈压力测定はバ ラトロンで行なった。

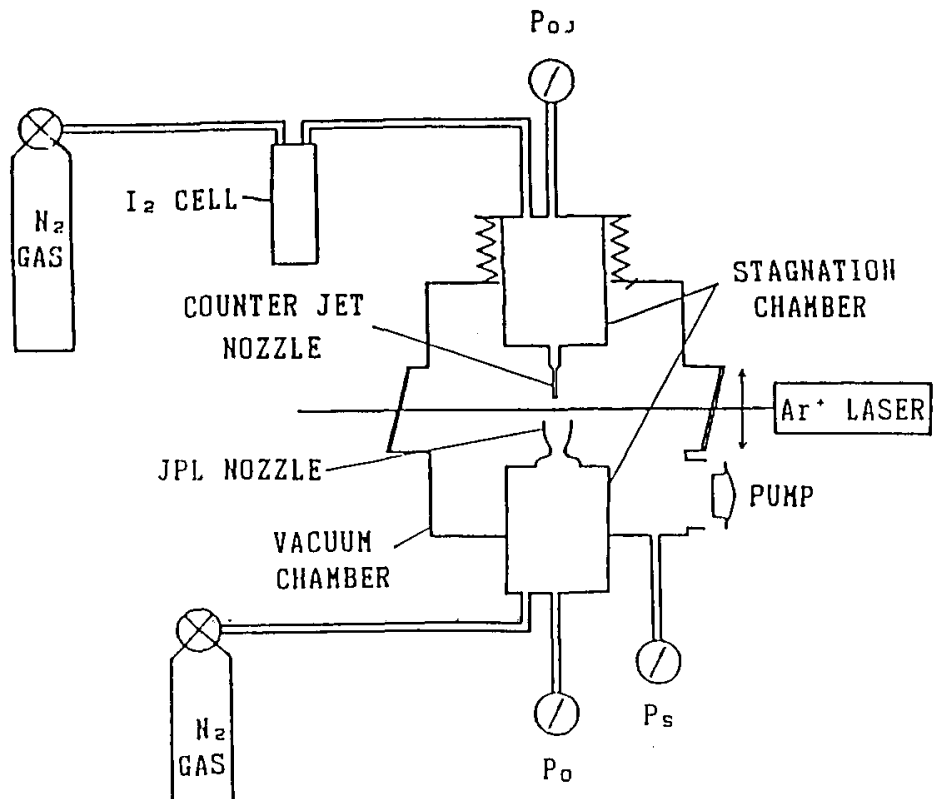

Fig.1

Schematic view of experimental apparatus

( J P L ノズル総压 $P_{\text {o }}=300 \mathrm{Torr}$, 逆咕 射 ジェット総圧PoJ=100 7600Torr) Counter Nozzle J P L Nozzle

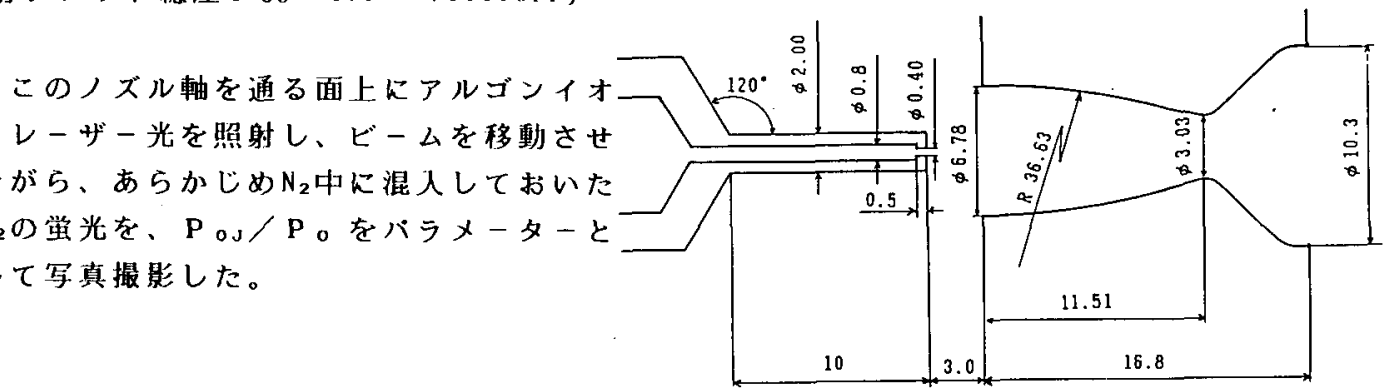

Fig.2 Nozzle dimension

\section{3. 実験結果}

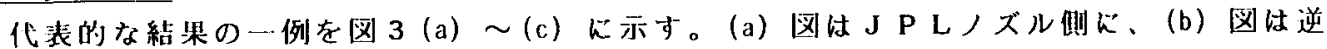
嘪射シェットノスル例に I 2 を加えた場合であり、この二つの可視化写真より流れ埸を把 握できる。比較のため逆貲射を行わない場合の流れ場を(c)に示す。写真で下側の部外に 虫光が認められないのは逆顀射ジェットノズルによりレーザー光が遮らわるからである。 レーザー誘起监光法は、接触面が識別できることが大きな利点であるが、この他に(a) 困 では離脱语整波が、(b)図では内部语整波が明確に現れている。次に逆䚓射ジェットノズ ル側にI2を加えて压力比を变えた場合の結果を図 4 に示す。(a) 〜 (c) の様に压力比が 大きいときには、内部衙揧波と接触面の位置が明確に読みとれるだけでなく、内部衙慗波 とジェット境界の干涉により内部衙整波の端から営光部が伸びているのが観察できる。従 来の研究によれば逆噴射シェットの流れ場は大别して3つの領域に分けられる事が報告さ れていたが、本状喼は安定領域に相当すると考えられる。(f)では境界が不朋瞕となって 
いるが、これは内部璄撃波が振動しているためであると推測できる。これより(f) は不安 定な領域であると考えられる。(d) 〜 (e) は両者の中間域にあたるものであろう。このよ

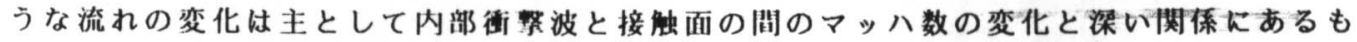
のと考えられる。

\section{4. 結論}

本研究によりレーザー誘起虽光法を用いると、シュリーレン法では充分把握できなかっ た接触面形状などの逆嗔射ジェット内部構造が明暸に把握できることが明らかとなった。 また、従来から報告されていた流れの不安定現象も捕えることができた。今後はジェット 圧力比をバラメータとして定量的な実験を進めていく。

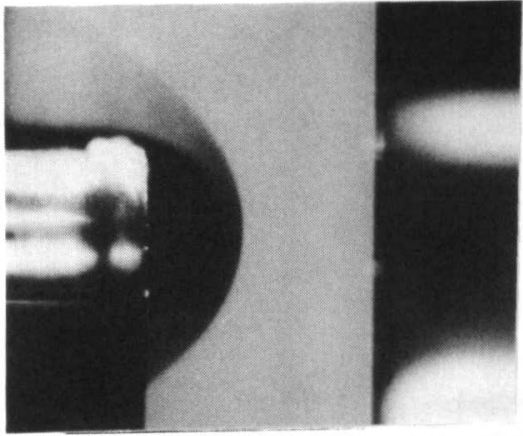

(a) $P_{0 J} / P_{0 \infty}=1.27$

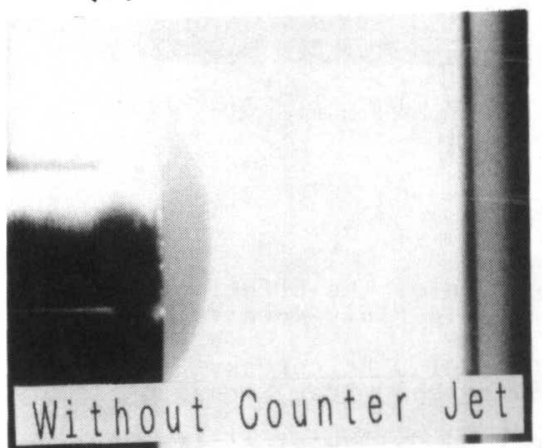

$(c) P_{0 J} / P_{0 \infty}=0.32$

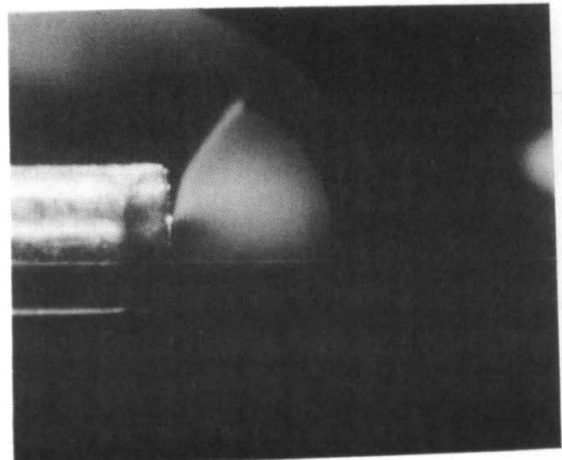

(a) $P_{0 J} / P_{0 \infty}=14.73$

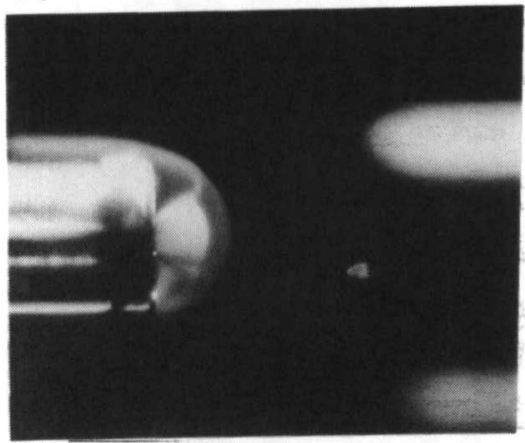

(b) $P_{0 J} / P_{0 \infty}=1.27$

$$
\begin{aligned}
& M=3.0 \\
& M_{J}=1.0
\end{aligned}
$$

Fig.3 Visualization of Counter Jet by LIF

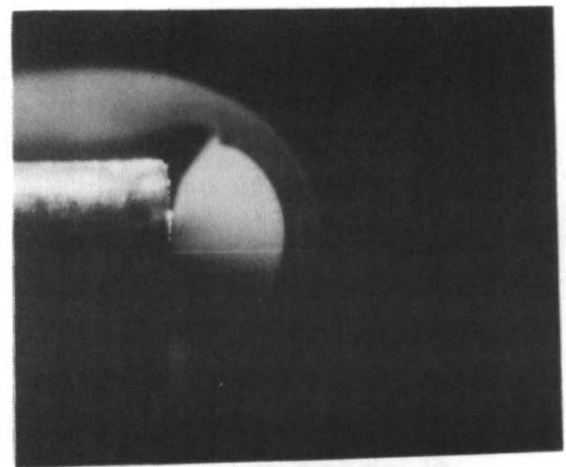

(b) $P_{0 J} / P_{0 \infty}=7.18$

Fig.4 Visualization of Counter Jet by LIF 


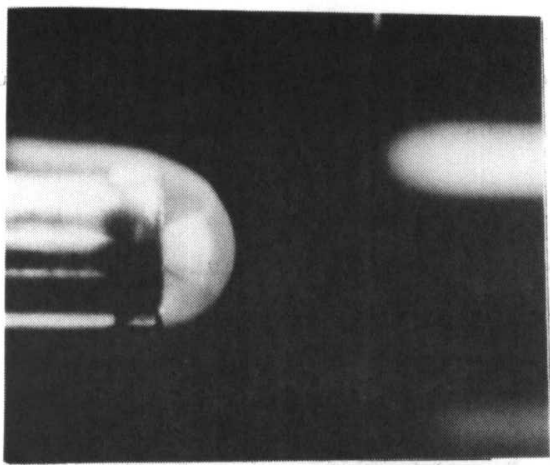

(c) $P_{0 J} / P_{0 \infty}=1.65$

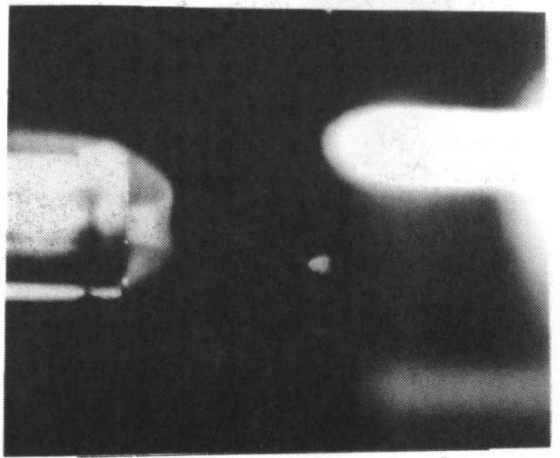

(e) $P_{0 J} / P_{0 \infty}=0.70$

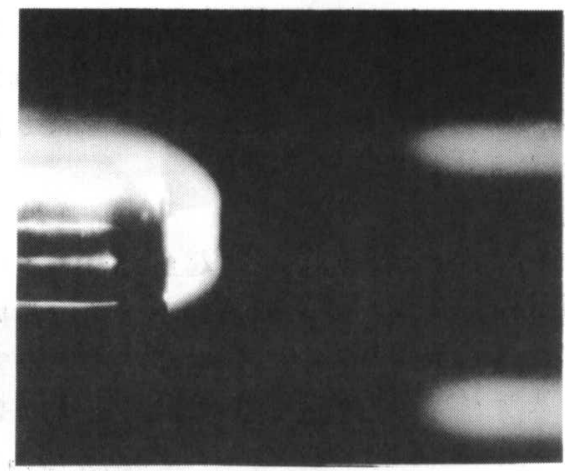

(d) $P_{0 J} / P_{0 \infty}=0.77$

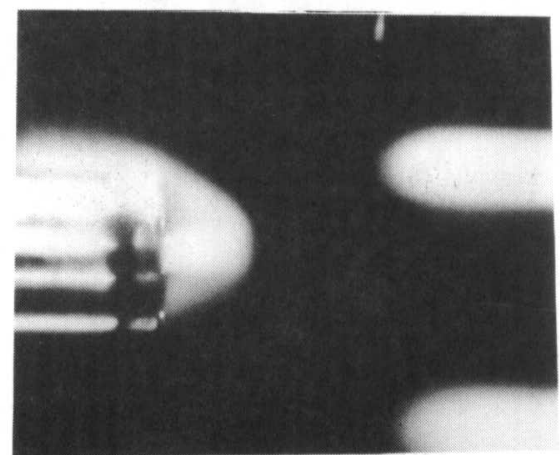

(f) $P_{0 J} / P_{0 \infty}=0.41$

Fig. 4 (Continued)

参考文献

[ 1 ] C.H.E.Warren,An Experimental Investigation of the Effect of Ejecting a Coolant Gass at the Nose of a Bluff Body,J.Fluid Mech.Vol.8, No.8, part3 (1959), pp. 400-417

[ 2 ] N.Charczenko, K.W.Hennessey, Investigation of a Retrorocket Exhausting from the Nose of a Blunt Body into a Supersonic Free Stream,NASA TN D-751 (1961)

[ 3 ] L.0.Hayman, Jr., R. McDearmon, Jet Effect on Cylinderical Afterbodies Housing Sonic and Supersonic Nozzles which Exhaust against a Supersonic Stream at Angles of Attack from 90 to $180^{\circ}$, NASA TN D-1962 (1962)

[4] J.R.Baron, E.Alzner, An Experimental Investigation of a Two-layer Invicid Shock Cap due to Blunt-body Nose Injection,J.Fluid Mech., Vol.15,part3 (1962),pp.442-451

[ 5 ] D.J.Romeo, J.R.Sterrett, Explorationary Investigation of the Effect of a Forward-facing Jet on the Baw Shock of a Blunt Body in a Mach Number 6 Free Jet Stream, NASA TN D-1605 (1963)

[6] C.Y. Wang, Countours for Stagnation-Point Mass Injection in Hypersonic FIOW, J.AIÁ, Vol.2, No.1 (1964), pp.178-179

[ 7 ] A.F.Charwat, Interraction Flows due to Supersonic Secconderry Jets, Jet, Rocket, Nuclear, Ion and Electric Propulsion(W.H.T. Loh,ed.,Berlin, Heidelberg, New York: Springer) p.487

[8] P.J.Finley, The Flow of a Jet from a Body Opposing a Supersonic Free Stream, J. of Fluid Mech.vol 26 , part 2 (1966), pp.337-368

[9] R.A.Cassanova,Flow Fieid of a Sonic Jet Exhausting Counter to a Low -Density Supersonic Airstream,Phys. of fluid, Vol.12, No.12(1969),

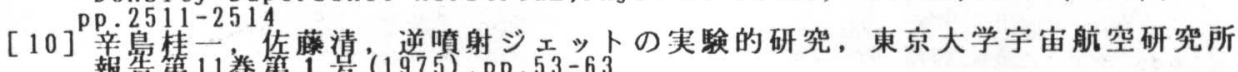
報第 11 巻第1 基 $(1975)$, p p . 53-63

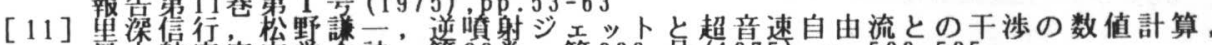
青㷊航空宇䆒学会誌, 第23巷, 第262 号(1975), pp.586-595

[12] K.Teshima,M. Sommerfeld,Visualizaion and Numerical Simulation of Super -sonic Microjets, Experiments in Fluids 5, (1987), pp.197-200 